\title{
Normal Education System in Australia and China
}

\author{
Yili $\mathrm{Hu}^{1, \text { a, },+}$, Xintong $\mathrm{Shi}^{2, \mathrm{~b}, *, \dagger}{ }^{*}$, Ziyue Sun ${ }^{3, \mathrm{c}, *, \dagger}$ \\ ${ }^{1}$ School of Arts, University of Melbourne, Melbourne, Victoria, 3000, Australia \\ ${ }^{2}$ School of Education Science, Nanjing Normal University, Nanjing, Jiangsu, 210046, China \\ ${ }^{3}$ Faculty of Education, Monash University, Melbourne, Victoria, 3199, Australia \\ *Corresponding author email: ${ }^{a} y i l i h 1 @$ student.unimelb.edu.au, ${ }^{b} 04180208 @ n j n u . e d u . c n$, \\ cyhua367@student.monash.edu. \\ Those authors contributed equally.
}

\begin{abstract}
Normal education is a crucial approach to training excellent teachers. Both China and Australia have their normal education systems. However, owing to the diversities in politics and culture, the normal education of both countries has similarities and differences. The paper compares the normal education program in two countries, and we focus on the programs in the Universities that are prepared for future primary school teachers. The paper reviews the public documents, the research from both countries about their own national normal education development, and some research specifically discuss comparing primary teacher training system between China and western countries. Firstly, the paper compare the professional standards for teachers set by the department of education in both countries as the pitching in point. Then, understanding the correlation and gaps between theory learning and educational practice according to the social background of the two countries. The endpoint of the paper is with firstly, the social and cultural background lead to different design and adopting of the educational theories and practices in the educational program in the universities. The authors are aware that the nature of comparative education is to investigate two different forming of social context in two different regions. Secondly, although the designs of the normal education programs in universities in two countries and the reasons behind the design are different from beginning to end, the needs for professional support of the graduate teachers are similar. The governments in both countries take a positive attitude in managing the professional engagement of the graduate teachers.
\end{abstract}

Keywords: Normal Education, Pre-service Teachers, Comparative Education, Standard for Teachers, Australia, China.

\section{INTRODUCTION}

It has been widely acknowledged that the key to promoting educational development is normal education [1]. This is because the educational development for high-quality human resources in a country is considered one of the standards to evaluate the national strength [1]. Both Australia and China pay efforts to develop normal education. Retrieved from government documents, in Australia, the professional standard for teachers is firstly issued in 2003 and been revisited in 2011 and 2016 [1]. In China, the first version of the professional standard of teachers is issued in 2012, and it experiences a period of academic review and trial implementation [1]. To discuss the professional effort and the public awareness, in Australia, the government appoints researchers to identify and analyze the longitudinal relationship between national normal education and teachers as workforce [2]. The research and data provide guides for the Australian government to thinking about mutually beneficial interventions for both the faculty of normal education in the universities and the social working. In China, President Xi visits Tsinghua University on 19th April in 2021 and enhances the importance of normal education in a seminar available to the public and the news. Xi affirms that "teachers are the backbone of educational development. Without high-quality teachers, it would be difficult to cultivate human resources with quality innovation and produce quality achievements." [3] The warm regard toward the normal education program from the government and the public in both countries provides the rationale of this review interest. To be specific in this review paper, the authors choose normal education provided by the faculty of education in universities as the range of the review. It is because 
courses from universities are regarded as a representation that is officially supervised and acknowledged rather than organizationally diversified as the other two. Meanwhile, the specialization is selected to be the normal education for primary school teachers. This is because primary education is compulsory and has the most amount of stakeholders in a country. The paper compares the objective for future teachers, the particular course designs in the normal education program, and diagnosing the common deficiencies in the two countries of their normal education.

\section{THE OBJECTIVE OF THE NORMAL EDUCATION IN CHINA AND AUSTRALIA}

In terms of the design of normal education, we make a comparison between Professional Standards for Students of Primary Education in 2021and Australian Professional Standards for Teachers [APST] in Australia $[5,6]$. There are four parts of major abilities in Chinese professional standards, which are 1) educational code of ethics; 2) teaching ability; 3) ability of comprehensive education, and 4) ability of self-development. Meanwhile, APST has graduation requirements for preservice teachers from seven aspects, including "know students and how they learn, know the content and how to teach it, plan for and implement effective teaching and learning, create and maintain supportive and safe learning environments, assess, provide feedback and report on student learning, engage in professional learning, and engage professionally with colleagues, parents/careers and the community" [5]. By comparing the professional standards of normal students in two countries, we found the following similarities and differences.

\subsection{Similarities}

Firstly, both countries value the teaching ability important[5-7]. To explain, in China, the expectation toward professional teaching ability reveals through pedagogical knowledge, lesson design, and course teaching, which belong to the second category of teaching ability in the professional standards[6, 7]. APST has a similar requirement for pre-service teachers that teaching content and methods, teaching plan and implementation, and learning environment [1, 5]. Secondly, both countries are concerned about professional learning abilities and cooperative communication abilities during employment [1, 4]. The fourth part of the Chinese professional standards is the professional ability to self-improvement and teamwork during employment. The sixth and seventh parts of the Australian professional standards put forward the same requirements on these two aspects and increased engagement professionally with students' carers and the community.

\subsection{Differences}

According to the professional standards of the two countries, they emphasize differently. To explain, China's professional standards allow teachers to analyze themselves [6-8]. Meanwhile, APST emphasizes analyzing students $[1,5]$. In China, the professional standards aim to improve teachers' multilateral abilities, for example, the moral beliefs and the teaching methods, with only one strand mentions paying attention to students $[1,7,8]$. However, in APST, the first point is to allow teachers to understand physiological characteristics, religious and cultural background, and learning the way of students [1, 5, 9]. Moreover, Ma's comparative research also found that the Chinese standard addresses more for cultivating morality than Australia [1]. In detail, the first point of the standards is the professional ethics of teachers, as well the third point contains morality training and behavior training of students [5].

\subsection{The Reasons for the Differences between China and Australia}

The above differences are related to the discrepancies in the social-cultural background between the two countries. To explain, collectivism orients the moral principle in socialist China, while western culture enhances individualism [10]. These social guidances overwhelm the educational system, and the professional standards of teachers are following through $[7,8,11]$. To be specific, in China, as the socialist core value consistent with collectivism, [12] one of the fundamental models in Chinese compulsory education is managing students in a class as one group. It advocates the idea of constructing the class and form a class culture [13].

Also, the composition of the demographical factors such as race and ethnicity in the society leads a specific expectation to the role of schools [1]. As most students in Chinese schools are born and grown locally, and most Chinese are nullifidian, the demographic composition is relatively onefold $[7,8,11,12,14]$. Students in a Chinese classroom or school may have a similar cultural background [14]. Therefore, pre-service teachers are taught to manage the students as a collective group, establishing common discipline and pay less attention to the individual differences among students [12]. In Australia, since the policies show a considerate attitude toward overseas human resources and refugees, as well as the citizens with Aboriginal and Torres Strait Islander lineages, $[9,14]$ the teachers in school respect and value individual differences to respond to the cultural environment [15]. For example, the pre-service teachers are taught to adjust teaching method for students with different cultural backgrounds, such as designing lesson plans for learning about Asian paintings, to allow Asian immigrant students in Australia to feel their identity is 
approved and build their sense of belongings to the school $[2,5,9]$. The requirement is specifically set for teachers who are teaching in Australia, which is different from the unified lesson design in Chinese elementary schools.

Then, the specific national conditions influence the expectations to graduate teachers in two countries, that Chinese universities put an extraordinary eye on ideological and moral education and Australian universities strengthen pre-service teachers' characteristic and personal feature [1, 4-6]. In detail, in China, professional ethics is the key part when evaluating teachers. To be noticed, both teachers and students have to receive ideological and moral education throughout their whole student life, in the form of class meetings or mentioned in random courses [7, 8, 12]. In Australia, normal education firstly displays the classic and wellknown educational and developmental theories to preservice teachers, then requiring them to reflect on their own experiences and using examples to combine the theories and their application [2,9]. Thus, the pre-service teachers develop unique teaching styles that critically reflect their own characteristics while studying theories. $[9,14]$.

Generally speaking, owing to the differences in national conditions and social culture, the objective of the normal education between two countries has differences. Importantly, these differences result in the different focus of the design of the education program, especially for the curriculum settings of the two countries, which will be elaborated on in the next section.

\section{DESIGN OF THE NORMAL EDUCATION}

The following paragraphs would introduce specific examples of the design in the educational programs that correspond to the above objectives in both countries.

\subsection{Designs for Meeting Teaching Abilities Needs}

Both China and Australia pay attention to the teaching ability of teachers, which is defined as the ability to practically teach in classrooms and the professional degree to collaborate in the education team after setting in. In China, the universities provide preservice teachers with opportunities for Placement in Regular Workplace [Ding Gang Shi Xi] [4, 16]. To explain, Placement in Regular Workplace is a sort of internship for pre-service teachers who have the initial ability to work independently in practical positions [16, 20]. It offers practical exercises and relevant teaching experiences before they are officially hired. It is defined as the most effective way to transform the theoretical knowledge learned from school into practical experiences $[4,16,20]$. In addition, experienced room leaders that are work at the frontline in the target school are appointed to be the mentors and are expected to constantly negotiate and review the pre-service teachers' learning plan $[8,11,16]$. The instructors would give feedback and scores based on the interns' performance in the classroom, communicating the teaching methods to adapt to the professionalism in the classroom faster, which can also promote their ability to cooperate and coordinate after employment $[16,20]$.

Meanwhile, pre-service teachers in Australia are also enhanced with the teaching ability. The units include the scaffolding of the discipline knowledge concepts and focus on the teaching method. For example, the unit "science and technology education in the primary years" discusses inquiry-based approach, problem-based approach, etc., as frameworks that conduct the complex and rich concepts to primary school students [17]. For instance, pre-service teachers are taught to guide students to identify a global or local issue such as water pollution and provide them with makers' spaces and rich resources and materials like cotton and carbon sticks to design sewage filters $[9,17]$. The design of the teaching method encourages each individual student to adopt their science knowledge and fully participate, and develop problemsolving skills, collaborative skills, and creativity $[1,14$, 17]. The pre-service teachers improve their practical teaching ability by learning the teaching approaches.

\subsection{Design for Chinese Educational Code of Ethics}

China's professional standards focus on teachers' self-awareness and moral belief development. Yang indicates that it is emphasized that the independent development of the pre-service teachers ultimately influences the transition period to careers [4]. The preservice teachers are learned to strengthen the professional beliefs of teachers and their professional recognition [4, $7,8]$. They not only treat teaching jobs as a means of earning a living, but a kind of pursuit of life goals, to produce the concept of compliance, belief, and respect for the teaching profession $[7,8,11]$. Therefore, when encountering difficulties, they would have strong beliefs to actively cope with problems. Taking teachers' professional faith as a teacher to become their internal driving forces, growing in a long professional career, constantly learning to improve themselves, helps normal students gain greater achievement in teaching [4].

\subsection{Design for Australian Individualization}

In the education program in Australia, the courses are designed to lead pre-service teachers to observe the current level shown by the students at all times [18], including watching and recording students' performance on tasks, questioning students, and carefully listening to their verbal responses. Importantly, pre-service teachers also need to learn how to use formative assessment and 
summative assessment to learn more about students' learning. Regard the children's literature, storytelling, and the course of the arts as an example. The professors show the pre-service teachers with appointed storybooks used to assess the student's reading ability [19]. Specifically, there are levels of literacy skills from 1-18, and each level corresponds to different difficulties in detail. Students are assessed individually by reading the storybooks from their recorded level. The pre-service teachers learn to observe and document children's intonation, pronunciation, reading behavior, pauses, fluency, vocabulary, comprehension level, etc., to understand the abilities and progress of each child in the class [18, 19]. Therefore, teachers evaluate the documentation to set an individual developmental direction for the child to improve his or her specific current literacy level $[1,6,9,14,17,18]$.

\section{THE DEFICIENCIES OF THE NORMAL EDUCATION}

The following part of the paper would discuss the gaps between the objectives and the outcomes of the normal education after conducting the education program in the two countries. The gaps are focusing on, firstly, the early career leaving [2, 21, 22] with attribution of graduate teachers' ambiguous ethical standard and beliefs on teaching career $[2,4,9,11]$. The second gap is graduate teachers' inadequacy of collaboration and communication skills when work and develop in the school as a whole teaching team in both countries [1, 4, 21]. These deficiencies would be explained with reasons from the current research, justified with examples, and provided with future application from the academic field.

\subsection{Early career leaving, is it solely attribute to unstable career beliefs}

First of all, both Chinese and Australian graduate teachers receive a similar comment from both their contextual societies that they have "unstable career beliefs" [4, 20, 21]. It is explained as a high proportion of leaving the career within their first three years of entering the occupation of teaching [2, 4, 9, 21]. Studies before the 2010s attribute the reason for this phenomenon to the inadequacy of the educational code of ethics in the preservice training content $[4,16,20,22]$. However, research after 2013 against the previous studies, which analyze the phenomenon by investigating why new teachers leave a career and the original intention of preservice teachers, choose the educational program in universities [4, 21]. To show results, in both countries, the distribution of the leaving career reasons remains similar, which is heavy workload $(53.6 \%)$, insufficient recognition and reward (44.5\%), better chances outside the school, lack of human resources support, and unsatisfied with the immature assessment and praise process [21]. To be noticed, the new teachers' original intention of choosing an educational program in universities in the two countries is in contrast. It gives an implication that it is controversial to say the unstable career faith leads early career leaving. To display the data, in China, the professional passion of pre-service teachers shows originally low and passive $[4,11]$. To be specific, $27.7 \%$ of the pre-service teachers reckon they choose education program because "teachers' job is stable", $27.8 \%$ respond "I can't find another appropriate job" and "my parent made this decision". There are $51.4 \%$ of the new teachers answer "no" to the question "If you have a chance to choose again, will you still be a teacher?" [4]. In Australia, the original intention for preservice teachers to choose education programs in universities shows primitively optimistic. For examples, $80 \%$ of the education program students respond they "love teaching", and the later four motivations queueing are "desire to work with young people" $(77.7 \%)$, "desire to contribute to society" (52.7\%), have "family role model(s)" (26.4\%) and "encouragement from the teacher(s) while you were at school" (21.9\%) [21].

The above data reflect a common existing issue in graduate teachers: early career teachers leave the occupation irrelevant to ethical belief and professional passion. This paragraph shows the future implication of both the national education department for recovering the early leaving issue.

Presently, both Chinese and Australian researchers are striving to investigate a mature transition process for prohibiting the loss of new teachers $[4,16,20,22]$. In China, researchers establish a "U-G-S" (stand for University-Government-School) multilateral development model for early career teachers' orientation $[4,7,11]$. Specifically, the strategies include the following ways. 1) The school uses the allocated funds from the government wisely to set bonuses, improves the teaching facilities, and embellishes the working environment. 2) The school initiates activities for the new teachers to be quickly included by the staff team. They can display their strengths through the activities to establish self-efficacy and first conversation with the old staff. 3) The school arranges a light workload for the early career teachers, for providing graduate teachers adequate time to commit self-professional development that integrating their theoretical learnings from the universities to the practical strategies and reflecting and evaluating their own professional performance [4, 16]. Also, in Australia, researchers point out to learn from Stanford Universities in the United States about the induction period to improve early career teachers' performances and working satisfaction [2, 9, 21].

\subsection{Inadequacy of collaboration and communication skills}


The graduate teachers find collaboration and communication as the compulsory abilities after transiting into an occupation, however, the major of primary education in universities in both countries pay less attention to enhancing pre-service teachers' awareness on communicating with all stakeholders include students, colleagues, parents, school administrators, community residents, etc. [4, 11, 22, 23]. To be noticed, high accomplish teachers collaborate with a whole village to educate.

It is shown Chinese and Australian graduate teachers are weak to collaborate with different stakeholders. In China, graduate teachers find hard to establish a connection with students [4] and in Australia, graduate teachers find hard to communicate with parents from the diverse cultural background [2, 21]. For example, in China, $40 \%$ of the new teachers find they face obstacles when communicating with students, and $30 \%$ say they "do not know how to make friends with students" [4]. Also, the Chinese graduate teachers have received comments of "choose a naive method when managing students' problem behaviors" from the senior teachers [4]. In Australia, the communication with families stays at a surface that graduated teachers solely describing students' daily routine, instead of establishing empathy, gaining a deeper understanding of the specific family's background, and setting common developmental goals for an individual student [2, 9, 21, 23].

Although it is taken for granted that early career teachers contain insufficient social networking experiences, the researchers in the two countries investigate the direction to improve this problem among early-career teachers $[4,8,11,16,20,22]$. In China, lesson study as a group professional development approach in the schools helps early career teachers gain leadership and collaborative skills to manage the relationship with students [24]. In Australia, the education program in universities set education leadership courses, which conducts strategies for involving every stakeholder's voice in the school. The future changes are aiming at turning the pre-service teachers into holistic decision-makers and effective communicators [5, 9, 25].

\section{CONCLUSION}

In conclusion, this paper reviews and compares the 1) the objective of normal education; 2) the design of normal education; 3 ) the deficiencies of normal education between Australian and Chinese major of education in universities with a specialisation of primary education in a sequence. As the objective, similarly, both countries' normal education focus on pre-service teachers' teaching ability. Related placement and courses about pedagogical approach are designed to improve pre-service teachers' professional ability. Differently, it is discovered that China focuses more on the teaching ability to arouse students' awareness on collectivity and moral ethics by informing the pre-service teachers with the correct beliefs and behaviours of being in the Chinese social group. While the teachers in Australia are expected to pay more attention to individual students. Australian individualization pursuing inclusive and equity education for primary students with various abilities, languages, and backgrounds. Nevertheless, there are deficiencies of a high proportion of leaving the career in both countries, and the lack of collaboration and communication skill. The two deficiencies are respectively attributed to reasons of the graduate teachers have "unstable professional beliefs", and inadequacy of preparation for their career. However, new findings reckon the reasons are from the school and university disconnection. The paper also reviews the efforts that both countries put into covering the deficiency, such as establishing the "U-G-S" model, initiating activities for new teachers, and creating courses related to educational leadership in normal universities.

\section{REFERENCES}

[1] Ma, Y. (2015). Comparative of sino-australian professional standards for teachers. Master of Education in Science Dissertation, Graduate School of Henan University, 2015, G40-059.3

[2] Mayer, D., Doecke, B., Ho, P., Kline, J., Kostogriz, A., Moss, J., North, B. \& Walker-Gibbs, B. (2013). Longitudinal Teacher Education and Workforce Study [LTEWS] Final Report. Retrieved from https://www.researchgate.net/publication/3050614 32_Longitudinal_Teacher_Education_Workforce_ Study_LTEWS_final_report_November_2013

[3] Chinese Ministry of Education [MOE]. (2021). Notice issued by the Leading Party Members' Group of the Ministry of Education of the Communist Party of China on the in-depth study and implementation of the spirit of General Secretary Xi Jinping's important speech during his visit to Tsinghua University. $\quad$ Retrieved from http://www.moe.gov.cn/jyb_xwfb/s6052/moe_838/ 202104/t20210419_527148.html

[4] Yang, C.E. (2013). The adaptability of normal graduates to teachers and its counter measures. Education Exploration, 2013(11), 108-111. DOI: 10 $02-0845$ (2013) 11- $0108-04$

[5] Australian Institute for Teaching and School Leadership [AITSL]. (2017). Australian professional standard for teachers. Retrieved from https://www.aitsl.edu.au/teach/standards

[6] Standards China. (2021). Professional Standards for Students of Primary Education (Trial Implementation (360A10-04-2021-0006- 
1). http://www.moe.gov.cn/srcsite/A10/s6991/2021 04/t20210412_525943.html

[7] Deng, Y. H., Yu, J. \& Chen, H. G. (2009). Analysis on the curriculum design of primary education specialization in higher institution. Curriculum, Teaching Material and Method, 29(2), 78-82, DOI: 10.19877/j.cnki. kcjcjf.2009.02.020

[8] Lv, W. P. \& Song, J. (2017). Research on problems and solutions of undergraduate course setup in the major of primary school education - a case study of three normal universities. Theory and Practice of Education, 37(9), 39-41. DOI:1004-633X(2017)090039-03

[9] Ingvarson, L., Reid, K., Buckley, S., Kleinhenz, E., Masters, G. \& Rowley, G. (2014). Best practice teacher education programs and Australia's own programs. Australian Council for Educational Research. Retrieved from https://www.dese.gov.au/teaching-and-schoolleadership/resources/best-practice-teachereducation-programs-and-australias-own-programs 1

[10] Li, X. T.(2020). Realistic thinking on the differences and integrations of Chinese and western cultures. New West, (18), 89-90. doi:CNKI:SUN:XXBL.0.2020-18-051.

[11] Li, D. Z \& Liu, H. X. (2016). Five links between training of normal students and elementary education. Journal of Educational Science of Hunan Normal University, 15(3), 81-99. DOI: 1671-6124 (2016) 03-0081-05

[12] Su, Q. X., Cooper, P., \& Sin, K. (2018), The 'learning in regular classrooms' initiative for inclusive education in China. International Journal of Inclusive Education, 22(1), 54-73, https://doi.org/10.1080/13603116.2017.1348547

[13] Zhang, C. (2019). Questioning and thinking on class education in China for 70 years: does class construction still make sense? Hubei Social Sciences, (12),160-166. doi:10.13660/j.cnki.421112/c.015288.

[14] Carringtona, S., Saggers, B., Adie, L., Zhu, N., Gu, D. Q., Hu, X. Y., Wang, Y., Deng, M. \& Mu, G. L. (2015). International representations of inclusive education: how is inclusive practice reflected in the professional teaching standards of China and Australia? International Journal of Disability, Development and Education, 62(6) 556-570, http://dx.doi.org/10.1080/1034912X.2015.1077933

[15] Hudson, A. H., \& Zhang, J. Y. (2003). Multicultural education and the postcolonial orientation. International and Comparative Education, 01(11), 17-34. doi:CNKI:SUN:BJJY.0.2003-01-002.
[16] Mao, W. X. (2020). Research on the quality assurance system of Placement in Regular Workplace [Ding Gang Shi Xi] in applicationoriented normal universities. Education and Professionalism, 2019(4), 80-85. DOI:10.13615/j.cnki.1004-3985.2020.04.014

[17] Fitzgerald, A., \& Corrigan, D. (2018). Science education for Australian students: teaching science from foundation to year 12 (Edition.). Allen \& Unwin.

[18] Cheeseman, J., \& Downton, A. (2021, week 8). Assessment of Mathematical Thinking: Building Assessment into a Mathematics Program.

[PowerPoint slides].

https://lms.monash.edu/course/view.php?id=92307

[19] Kummerling-Meibauer, B. (2017). The routledge companion to picturebooks (routledge literature companions). New York: Routledge.

[20] Shen, D. K. (2020). Study on the students performance evaluation from internship schools on Placement in Regular Workplace [Ding Gang Shi Xi] -- a case study of Qing Hai normal university's volunteer teaching internship in 2018. Higher Education Exploration, 2020(1), 48-54. https://www.zhangqiaokeyan.com/academicjournal-cn_higher-educationexploration_thesis/0201277450177.html

[21] McKenzie, P., Weldon, P., Rowley, G., Murphy, M. \& McMillan, J. (2014). Staff in Australia's schools 2013: main report on the survey. Canberra: Department of Education.

[22] Wu, Z. L. (2009). Training objectives and course orientation of Primary Education Major (undergraduate). Education Exploration, 2009(3), 33-35. DOI :1002-0845(2009)03-0033 -03

[23] Monk, H. The changing landscape of early childhood curriculum: Empowering pre-service educators to engage in curriculum reform (2018). In M. Barnes, M. Gindidis, \& S. Phillipson. Evidence based learning and teaching: A look into Australian classrooms. (Chapter 16). New York: Routledge.

[24] Doig, B. \& Groves, S. (2011). Japanese lesson study: teacher professional development through communities of inquiry. Mathematics Teacher Education and Development, 13(1), 77-93. Retrieved from https://files.eric.ed.gov/fulltext/EJ960950.pdf

[25] Victorian Curriculum and Assessment Authority. (2016). Victorian early years learning and development framework for all children from birth to eight years. Retrieved from https://www.education.vic.gov.au/Documents/childho od/providers/edcare/veyldframework.pdf 